\title{
Effect of Shockwave Intensity on Upper Limb Spasticity in Patients with Stroke
}

Hakimeh Adigozali ${ }^{1}$, Abbas Soltani ${ }^{2}$, Shirin Mohammadi ayan ${ }^{3}$

1. Assistant Professor, Department of Physiotherapy, Faculty of Rehabilitation Sciences, Tabriz University of Medical Sciences, Tabriz, Iran. ORCID ID: 0000-0001-8784-8992

2. Assistant Professor, Department of Physiotherapy, Faculty of Rehabilitation Sciences, Tabriz University of Medical Sciences, Tabriz, Iran., (Corresponding Author), Tel: 041-33375359, Email: ab.soltani@yahoo.com, ORCID ID: 0000-00027616-6627

3. MSc of Physiotherapy, Department of Physiotherapy, Faculty of Rehabilitation Sciences, Tabriz University of Medical Sciences, Tabriz, Iran. ORCID ID: 0000-0003-4505-4961

\begin{abstract}
Background and Aim: Spasticity following upper motor neuron lesions has adverse effects on patients' quality of life and performance. Shockwave therapy is a non-invasive treatment to reduce muscle tone. The purpose of this study was to evaluate the efficacy of shockwave intensity on the improvement of upper limb spasticity in patients with stroke.

Materials and Methods: In the present study, 20 patients with stroke were randomly divided into two treatment groups. Shockwave was applied for 1 session at the musculotendinous junction of flexor carpi ulnaris and radialis muscles using a low level of energy for group one $\left(0.03 \mathrm{mj} / \mathrm{mm}^{2}\right)$ and a high level of energy for group two $\left(0.8 \mathrm{mj} / \mathrm{mm}^{2}\right)$. The patients were evaluated at baseline and one week after the intervention. Upper limb spasticity and active range of motion of wrist extension were evaluated by Modified Ashworth Scale and goniometer, respectively.

Results: Upper limb spasticity and range of motion of wrist extension were significantly improved immediately and a week after high-intensity shockwave therapy. A significant decrease in upper limb spasticity and a non-significant increase in the range of motion of wrist extension were observed in the group receiving low-intensity shock waves.

Conclusion: High energy shockwave appeared to provide a beneficial effect on upper limb spasticity and range of motion of wrist extension, compared with low energy shockwave. It seems that treating with the appropriate intensity of shockwave may be an alternative method to other spasticity treatments.

Keywords: Spasticity, Shockwave, Upper motor neuron lesion, Range of motion, Rehabilitation Received: Sep 24, 2019 Accepted: June 25, 2020

How to cite the article: Hakimeh Adigozali, Abbas Soltani, Shirin Mohammadi ayan. Effect of Shockwave Intensity on Upper Limb Spasticity in Patients with Stroke. SJKU 2021;26(1):12-21.

Copyright (C) 2018 the Author (s). Published by Kurdistan University of Medical Sciences. This is an open access article distributed under the terms of the Creative Commons Attribution-Non Commercial License 4.0 (CCBYNC), where it is permissible to download, share, remix, transform, and buildup the work provided it is properly cited. The work cannot be used commercially without permission from the journal
\end{abstract}




\section{بررسى تاثير شدت شاكويو بر اسياستيسيتى اندام فوقانى در بيماران مبتلا به سكته}

\section{مغزى}

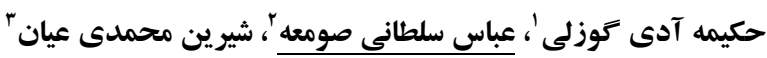

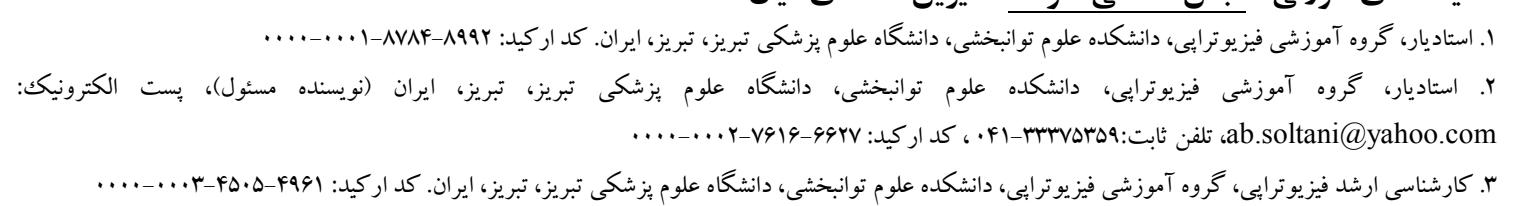

جكيده

زمينه و هدف: اسِاستيسيته به دنبال آسيبهاى نورون محر كه فوقانى اثرات سوئى بر كيفيت زنـدگى و عملكرد بيمـاران داشـته و

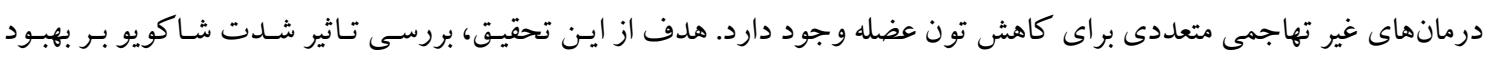

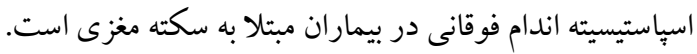

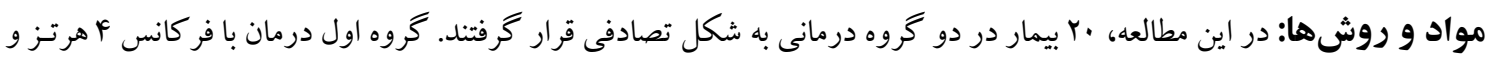

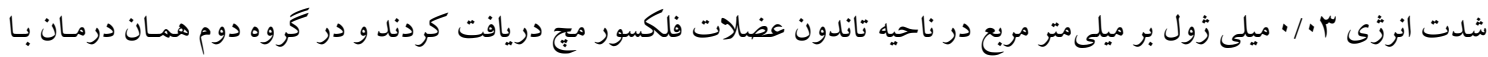

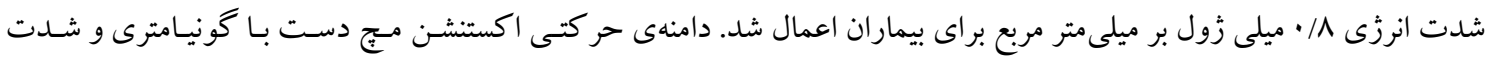

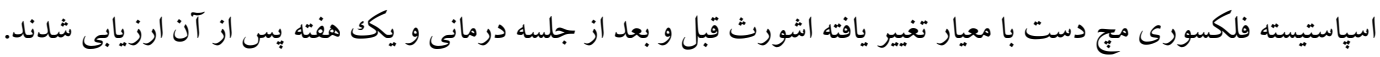

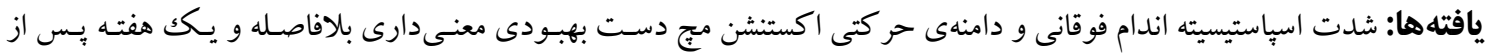

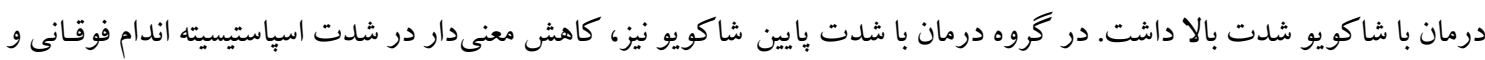

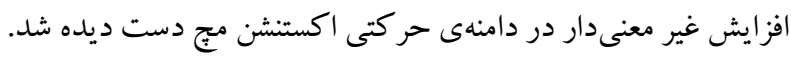
نتيجه كيرى: در اين مطالعه، درمان شاكويو با شدت بالا در بهبودى اسباستيسيته و دامنهى حر كتى بيماران در مقايسه با شدت بايين

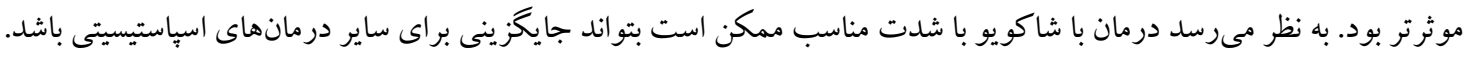

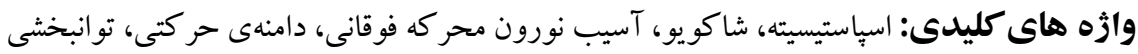

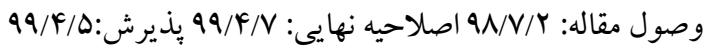


ميلىثانيه) است(9). مطالعات متعدد و تجربيات كلينيكى اثربخشى شاكويو در درمان بيمارىهاى تاندونى و استخوان مانند سودوآرتروزيس، تاندونيتهاى شانه، إيى كونديليت و التهاب فاشيا بخصوص در ورزشكاران را عنوان كرده اند. نتايج بدست آمده از كاربرد شاكويو براى درمان كانتر كجر و گزارشهاى اوليه از تاثير آن بر بيماران نورولوزيك مبتلا به هاييرتونيسيتى عضلانى، منجرشده تا اين روش بهعنوان

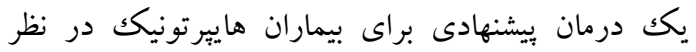

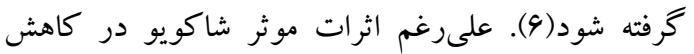
هاييرتونى ساير اختلالات حر كتى، مطالعات اندكى در زمينه

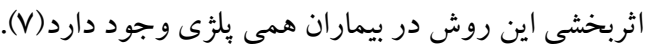

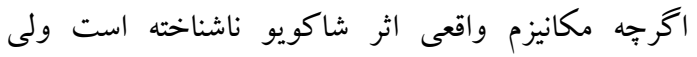
براساس نتايج تحقيقات بر روى حيوانات آشكار شده كه الثهات اولين اثر شاكويو تحريك ساخت بيش فاكتورهاى فر آيند

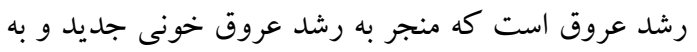

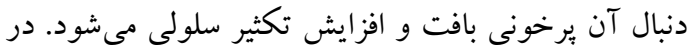

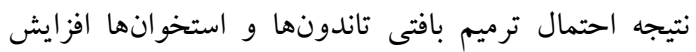

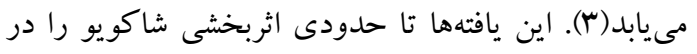
درمان آسيبهاى تاندونى كه از اولويتهاى كاربرد شاكويو

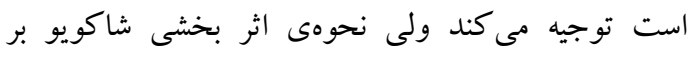
كاهش ميزان اسباستيسيتى در ضايعات نورون محر كه فوقانى جندان مشخص نيست. فرضيهاى كه در اين باره مطرح است كاهش ميزان كانتر كجر و كلسيفيكاسيون، تحريكك باز

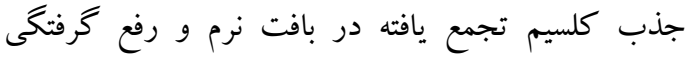
عضلانى مىباشد كه نيازمند بررسى است(^).

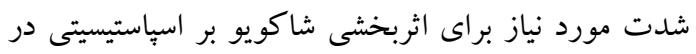
مطالعات مختلف به شكل متفاوتى گزارش شده است. در

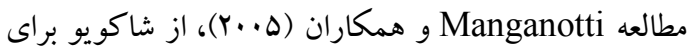
كاهش اسباستيسيته فلكسورى اندام فوقانى در ناحيه مج دست ·r بيمار مبتلا به سكته مغزى استفاده شد. نتايج حاصل از اين مطالعه، ضمن اشاره به بهبودى مشاهده شده در دامنه

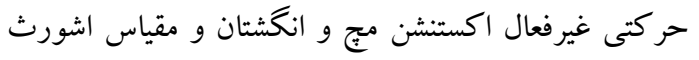

اسياستيسيته از عوامل مهم ايجاد ناتوانى در بيماران با آسيب

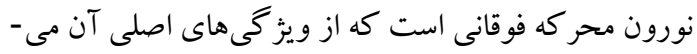
توان به افزايش تون وابسته به سرعت در رفلكسهاى كششى

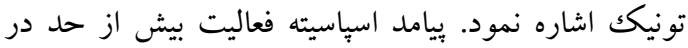
يرش هاى تاندونى همر اه با تشديد رفلكس كششى ( Stretch

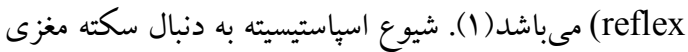
در هـ/ بيماران گزارش شده است و اندام فوقانى در حدود نيمى از اين بيماران بدون عملكرد باقى مىماند(Y). در واقع درجات بالاى اسباستيسيتى كه محدوديتهاى زيادى در عملكرد فرد ايجاد مى كند در اندام فوقانى بيشتر از اندام تحتانى ديده مىشود(r). بهدليل افزايش تون عضلات و فعاليت رفلكسى و همجنين كاهش كنترل مهارى بعد از آسيب نورون محر كه فوقانى، بيماران با مشكلاتى در زمينه كنترل حر كتى مواجه مىشوند كه نتيجهى آن، بروز اختلال

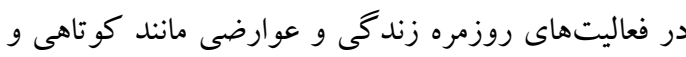
كانتر كجر عضلانى مى باشد(Y).

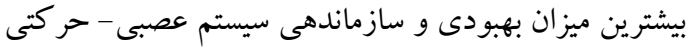
در 9 ماه اول بعد از آسيب نورون محر كه فوقانى اتفاق مى -

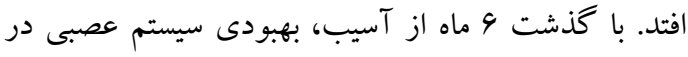
اين بيماران كند شده و با مشكلاتى نظير اسباستيسيتى و اختلالات حركتى مانند سين كاينزيس (حركتهاى غير لئس

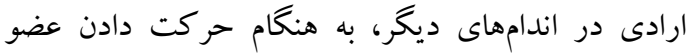

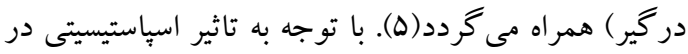

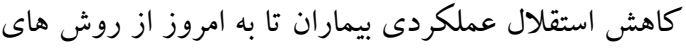
درمانى متنوعى براى رفع آن استفاده شده است(ه). قطع عصب، دنروه كردن با مواد شيميايى (بلوكى عصبى)، تكنيك هاى گج گيرى، اسييلنت، توانبخشى و تمرين درمانى

از جمله روشهاى درمانى رايج محسوب مىشوند (1).

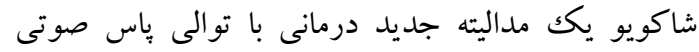

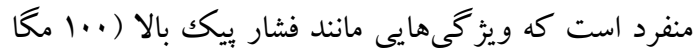
ياسكال) و افزايش فشار سريع داشته و زمان آن كوتاه (. 
آزمون آشنا شدند. معيارهاى ورود و خروج مطالعه به شرح

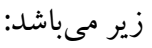

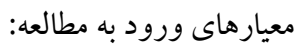

- بيماران مبتلا به سكته مغزى كه حداقل 9 ماه بِيش دجار

$$
\text { اين عارضه شده بودند. }
$$

- بيماران بر اساس مقياس تغييريافته اشورث داراى باى باد اسياستيسيتى زير نمره f بودند.

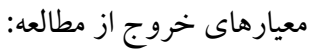

- استفاده از درمانهايى كه با مطالعه تداخل داشتند مانند

$$
\text { بوتولينيم تو كسين و فنول }
$$

- سابقه شكستخى و جر احى در ناحيه مجز دست و ساعد وند - داراى ضربان ساز قلبى بودند (بهعلت احتمال تداخل بين

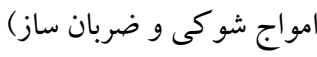

$$
\text { روش اجرا: - مان }
$$

الف) ارزيابى دامنه حى حر كتى فعال اكستنشن مج دست

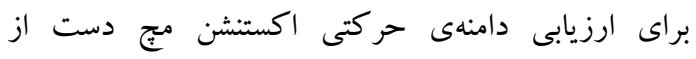

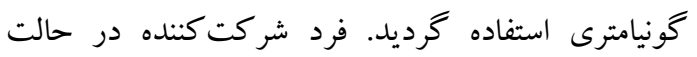
نشسته بر روى يكك صندلى دستهدارقرار گرفت و ناحيه مورد بررسى عارى از لباس بود به طوريكه نواحى استايلوئيد مج دست قابل لمس باشد. قبل از انجام گكونيامترى استايلوئيد اولنا، راستاى متاكاري يُّجم و راستاى استخوان اولنا نشانه-

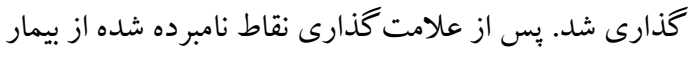

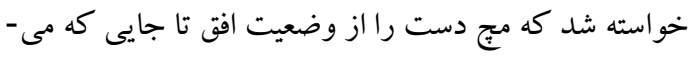

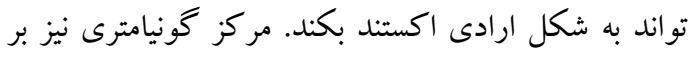
روى استايلوئيد اولنا و بازوى ثابت آن در امتداد ساعد و ودئي

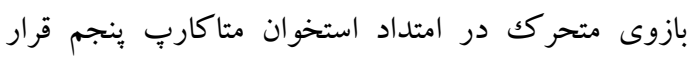

$$
\text { ب) ارزيابى اسباسيتيسيته فلكسورى مج دست: }
$$

براى ارزيابى ميزان اسياسيته اندام فوقانى در بيماران مبتلا

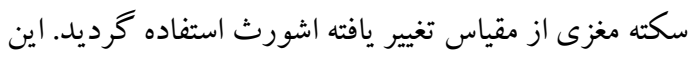
مقياس شامل بنج سطح مىباشد: صفر( عضله سفتى نرمال دارد)، يكك (عضله افزايش جزئى در سفتى دارد كه همراه
(Ashworth scale)، ماند گارى دامنهى حركتى اكستنشن

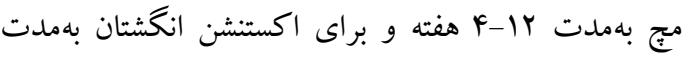

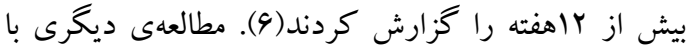
هدف مقايسه تاثير شاكويو بر روى ديستونى ثانويه و كرمب

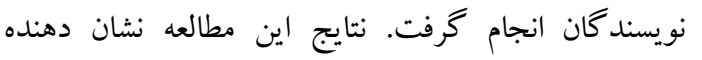

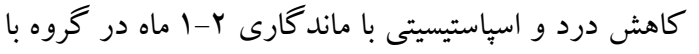

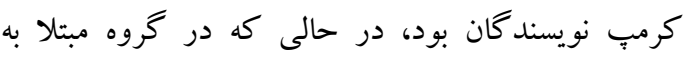

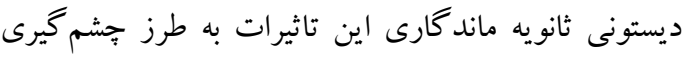
كمتر بود(9). در راستاى بررسى اثربخشى شاكويو مطالعلى ندي

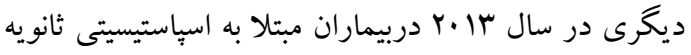

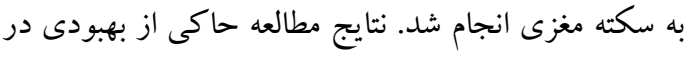

$$
\text { دامنه حر كتى و اسياستيسيتى بود (1). }
$$

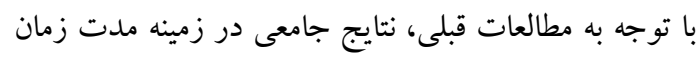

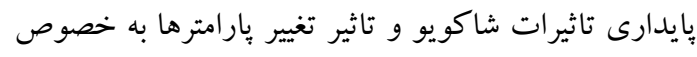

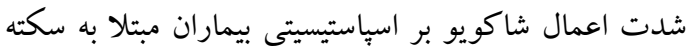

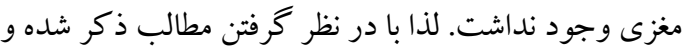
شيوع بالاى اسياستيسيتى اندام فوقانى(مخصوصا در ديستال اندام)، اين مطالعه با هدف بررسى تاثير شدت شاكويو در بدر

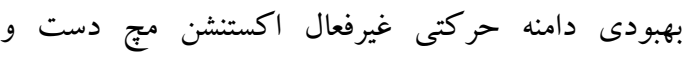
اسياستيسيتى فلكسورى اندام فوقانى در بيماران مبتلا به سكته دئه

$$
\text { مغزى طراحى و اجرا گرديد. }
$$

مواد و روشها

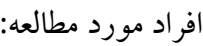
در اين مطالعه كارآزمايى بالينى يكك سويه كور، ·r بيمار مبتلا به سكته مغزى بس از بررسى از نظر معيارهاى ورود و

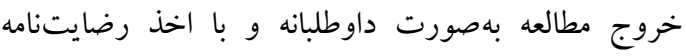
اخلاقى وارد مطالعه شدند.حجم نمونه باستفاده از نرم افزار

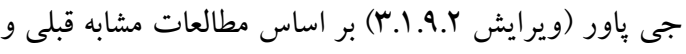

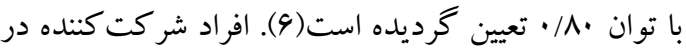

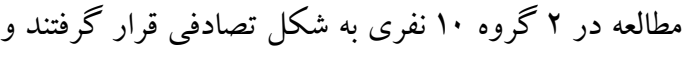

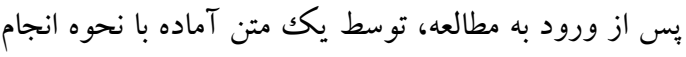

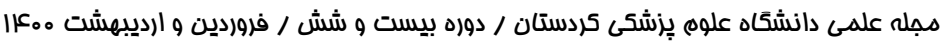


كاريى اولناريس و فلكسور كاريى رادياليس مج دست دريافت كردند. تعداد ضربات براى هر يكى از عضلات · ·ما ضربه بود. در گروه دوم (درمان با شدت بالا)

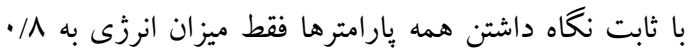
ميلىزٔول بر ميلىمترمربع تغيير ييدا كرد (تصوير شماره يكك). طول دوره درمان بيماران در هر دو گرووه يك جلسه بود و بلافاصله يس از اتمام مداخله، ارزيابىهاى بالينى قبل از درمان دوباره تكرار و ثبت شدند. ارزيابى نهايى نيز يك

$$
\text { هفته يس از درمان بود. }
$$
روش تجزيه و تحليل آمارى دادهها: تمامى آناليزهاى آمارى با استفاده از نرم افزار SPSS نسخه 1 صورت يذيرفت و از آزمون كولمو گروف اسميرنوف به منظور بررسى توزيع نرمال دادهها استفاده شد. سطح معنى دارى در اين مطالعه ه• • در نظر كرفته شد. بهمنظور مقايسه ميزان بهبودى در دامنه حركتى و شدت اسياستيسيته در افراد دو گروه قبل و بعد از درمان از آزمون تى زوجى و براى بررسى تفاوت بين گروهى از آزمون تى مستقل استفاده شد. اثر زمان نيز با اندازه گيرى مكرر بررسى گرديد.

بافته ها

جدول ا بيانكر اطلاعات دمو گرافيك افراد شركت كننده در دو گروه درمانى مىباشدكه متشكل از سا مرد و Vزن بودند. محدوده سنى بيماران ·FD-VA سال و ميانگين سن آنها • DV/LV سال بود. ميانخين طول مدت دركيرى نيز ماه بود. از نظر جنس، سن و مدت درگيرى با بيمارى اختلاف آمارى معنىدارى بين دو گروه وجود نداشت. در رابطه با شدت علايم (دامنه حر كتى اكستنشن فعال مج دست و ميزان اسياستيستى فلكسورى مج دست) در وضعيت يايه دو گروه تفاوت آمارى معنىدارى وجود نداشت (ه./.

$$
\text { . (جدول (P> (P) }
$$

دامنهى حر كتى فعال اكستنشن مجج دست در مقايسه با قبل از درمان در كروه اول افزايش داشت ولى اين افزايش از نظر

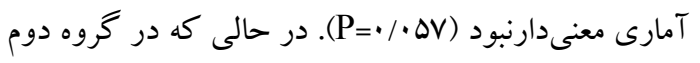

با كرفتكى مختصر در انتهاى دامنه حركتى غيرفعال است)، يكك مثبت (عضله افزايش جزئى در سفتى دارد كه همراه با كرفتكى مختصر در كمتر از نصف دامنه حركتى غيرفعال است)، دو (افزايش در سفتى بيشتر مىشود و كرفتخى در طى حر كت غيرفعال در بخش بزر كترى از دامنه حر كتى رخ مىدهد)، سه (سفتى بيشتر شده و انجام حركت به شكل غيرفعال سخت خواهد شد)، جهار (ريجيديتى رخ داده و انجام حركت غيرفعال غيرممكن مىشود)(1(1). براى انجام اين تست بيمار در وضعيت نشسته روى صندلى دستهدار قرار داشت و اندام فوقانى بر روى ميزى كه مقابل بيمار و متناسب با قد بيمار بود كذاشته شد. قبل از انجام تست مراحل انجام به بيمار توضيح داده شد تا از هر گونه اعمال مقاومت بيمار در مقابل انجام حركت غيرفعال توسط تراييست جلو گيرى شود. سيس ترايست در سمت درگير بيمار قرار مى گرفت و با يكك دست ساعد بيمار را ثابت نكه مىداشت، با دست ديخر ناحيه كف دست بيمار را طوريكه انگشتان بيمار در حالت عادى قرار داشته باشند گرفته و به شكل غيرفعال مج دست بيمار را اكستند مى كرد و براساس ميزان سفتى اندام

$$
\text { بيمار شدت اسياسيته نمره گذارى مى شد. }
$$

نحوه انجام مداخله:

براى انجام مداخله، بيمار به يشت دراز كشيده و اندام درگير با آرنج اكستند در سمت ترايست قرار گرفت و دستخاه شاكويو (ساخت كشور لهستان، مدل Astar-Impactis) نيز در همان سمت قرار داده شد. ناحيه تحت درمان شامل سطح يالمار ساعد و كف دست بود و توسط ترايست در ناحيه متج دست و انگشتان بيمار ثابت نكَه داشته مىشد. اين ناحيه بايد عارى از هر گونه زخم و مانعى بين بوست وبروب دستگاه بوده و در صورت لزوم پياكسازى مربوطه انجام مى گرفت. سبِ براى آمادهسازى قبل از شروع مداخله، موضع درمان

$$
\text { آغشته به زل لوبريكنت مىشد. }
$$

بيماران گروه اول (درمان با شدت بايين شاكويو) شاكويو را با فر كانس \& هرتز و ميزان انرزى ب•/ ميلىزول بر ميلىمترمربع در محل اتصال تاندون به عضله در عضلات فلكسور 
IV عباس سلطانى صوهعr

كاهش معنى دارى ديده شد (ه•/P>). اثر زمان نيز در هر

دو گروه معنى داربود (جدول ؟)، با اين تفاوت كه درمقايسه

دو به دو در گروه اول تفاوت معنىدارى در شدت

اسِاستيسيته هِ از يسك هفته از درمان نسبت به حالت قبل از

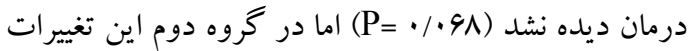

$$
\text { معنى }
$$

افزايش معنىدار براى دامنه ى حركتى اكستنشن مج دست

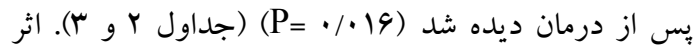
زمان در دامنهى حركتى فعال اكستنشن مج دست در كروه اول معنىدارنبود و تغيير معنىدارى يس از يكك هفته ديده نشد. در حالى كه اين اثر در گروه دوم معنىداربود (جدول

با مقايسه نتايج قبل و بلافاصله بعد از درمان در شدت اسپاستيسيته فلكسورى مجٍ دست در هر دو كروه درمانى

جدول ا. ميانكين و انحر اف معيار متغيرهاى دموكر افيك افراد شركت كننده در كروههاى درمانى (حجم نمونه هر كروه ده نفر مىباشد).

\begin{tabular}{|c|c|c|c|}
\hline PقدارP & كروه دوم (درمان با شدت بالا) & كروه اول (درمان با شدت يايين) & متغير \\
\hline.$/ 14$ & $F G(Y / Y \Delta)$ & $r \Delta(r / \Delta r)$ & سن (سال) \\
\hline.$/ Y r$ & $10 \Delta(1 / 9 \Delta)$ & $1 \Delta V(Y / 11)$ & قد (سانتىمتر) \\
\hline$\cdot / \mathrm{F}$ & $\Lambda Y(r / \cdot r)$ & $\Lambda \Gamma(1 / 10)$ & وزن (كيلو كرم) \\
\hline$\cdot / 99$ & $14 / .9(9 / 49)$ & $19(9 / F r)$ & مدت زمان در كيرى (ماه) \\
\hline$\cdot 1$ & FY/DG (A) & $\mathrm{Fr} / \mathrm{AD}(\boldsymbol{\varphi})$ & دامنه حر كتى (درجه) \\
\hline$\cdot / \cdot \wedge$ & $r / 4 r(\cdot / 9)$ & $r / 90(\cdot / V)$ & اسياستيسيته (كريد) \\
\hline
\end{tabular}

جدول ז. مقايسه ميانكين و انحر اف معيار دامنه حر كتى و شدت اسپاستيسيته در زمانهاى قبل با بلافاصله و يك هفته يس از درمان در

\begin{tabular}{|c|c|c|c|c|c|c|}
\hline \multicolumn{7}{|c|}{ كروه اول (حجم نمونه اين كروه ده نفر مىباشد). } \\
\hline $\begin{array}{c}\text { P value } \\
\text { (C) }\end{array}$ & $\begin{array}{c}\mathbf{P} \\
\text { value } \\
\text { (B) }\end{array}$ & يكى هفته بعد & $\begin{array}{c}\text { P value } \\
\text { (A) }\end{array}$ & بلافاصله بعد & دبل از & 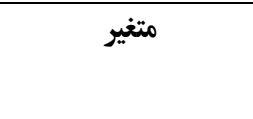 \\
\hline$\cdot / 49$ & $\cdot / \cdot \Delta r$ & $F F / \mu \Delta(\varphi)$ & $\cdot / \cdot \Delta V$ & $F V / l Q(V)$ & Fr/AD (9) & دامنه حر كتى (درجه) \\
\hline$\cdot / \mathrm{rr}$ & .1 .91 & $r / \Delta \Delta(\cdot / V)$ & $\cdot / \cdot \varphi_{*}$ & $r / l l(\cdot / 4)$ & $r / 90(\cdot / V)$ & اسياستيسيته (كريد) \\
\hline
\end{tabular}

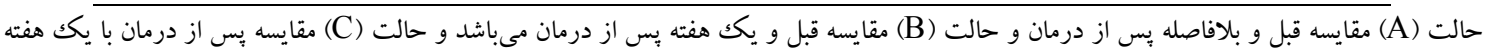

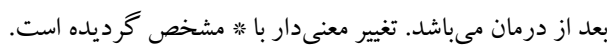

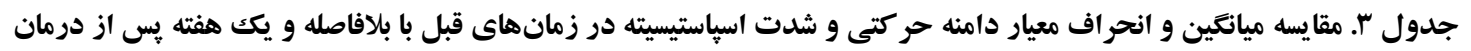

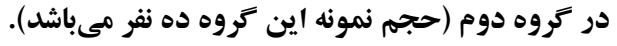

\begin{tabular}{|c|c|c|c|c|c|c|}
\hline $\begin{array}{l}\text { P value } \\
\text { (C) }\end{array}$ & $\begin{array}{c}P \\
\text { value } \\
\text { (B) }\end{array}$ & يك هفته بعد درمان & $\begin{array}{l}\text { P value } \\
\text { (A) }\end{array}$ & بعد ازلاصله & ق ق قبل از & متغير \\
\hline$\cdot / \cdot \mu^{\prime} *$ & $\cdot / \cdot V V^{*}$ & FA/VA (V) & $\cdot / \cdot 19 *$ & $\Delta I / K F(V)$ & Fr/DG (A) & دامنه حر كتى (درجه) \\
\hline.$/ K^{*}$ & $\because \cdots r *$ * & $r / 10(\cdot / \Gamma)$ & $\cdot / \cdots \Lambda_{*}$ & $1 / 19(\cdot / 0)$ & $r / 4 r(\cdot / 9)$ & اسياستيسيته (كريد) \\
\hline
\end{tabular}

هجلم علمى دانشكاه علوه بِزشكى كردستان / دوره بيست و شش / فروردين و ارديبرشت م.ع|| 
حالت (A) مقايسه قبل و بلافاصله پֶس از درمان و حالت (B) مقايسه قبل و يكك هفته پِس از درمان مىباشد و حالت (C) مقايسه بֶ از درمان با يكك هفته

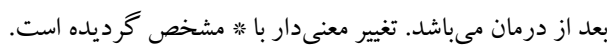

\begin{tabular}{|c|c|c|c|}
\hline سطح معنىدارى & $\mathbf{F}$ & متغير & كروههاى درمانى \\
\hline$\cdot / \Delta V^{\mu}$ & $F_{(F, r)}=\mid V / V 9 q$ & دامنه حر كتى(درجه) & كروه اول (درمان با شدت پايين) \\
\hline$<\cdot / \cdot \cdot 1 *$ & $F_{(F, r)}=\Lambda 1 / \Delta F q$ & اسياستيسيته (كريد) & \\
\hline$<\cdot / \cdots) *$ & $F_{(F, r)}=\Lambda F / 9.4$ & دامنه حر كتى(درجه) & كروه دوم (درمان با شدت بالا) \\
\hline$<\bullet / \cdot \cdot \mid$ 米 & $F_{(F, Y r)}=\Lambda r / Q q r$ & اسپاستيسيته (كريد) & \\
\hline
\end{tabular}

تغيير معنى دار با مشخص گرديده است.

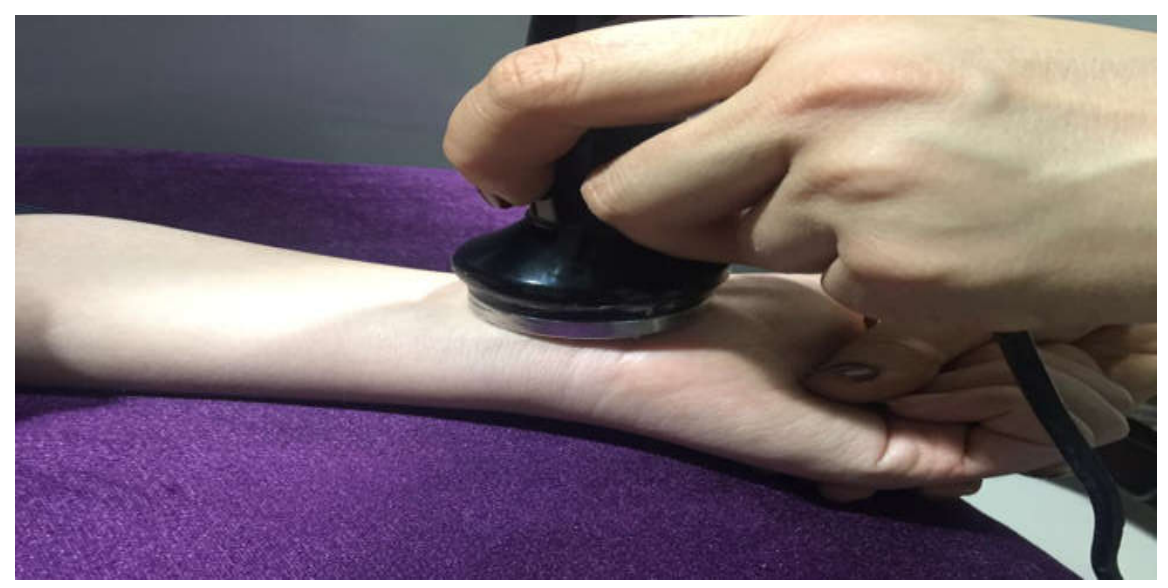

شكل ا. نحوهى درمان عضلات فلكسور كاريى اولناريس و فلكسور كاريى رادياليس مج دست بيماران مبتلا به سكته مغزى

\section{با دستغاه شاكويو}

(r) از جريان شاكويو به مدت دو جلسه درمانى در طول

دو هفته با ميزان انرزى ^/ • ميلىزول بر ميلى مترمربـع و . A در مطالعه حاضرتغييرات معنىدارى مبنى بر موثربودن اعمال ضـربه بــراى هركـــام از عضــلات فلكسـور سـاعد و بــين شاكويو در بهبودى اسياستيسيته فلكسورى مج دسـت در هـر استخوانى استفاده كردند و افزايش دامنـه حر كتى اكستنشـن دو كروه و افزايش دامنهى حر كتى فعال اكستنشن مج دست مج دست وانخشتان گزارش گرديد( •(1). در مطالعه Moon در گروه با شدت بالا در بيماران مبتلا به سكته مغزى يس از

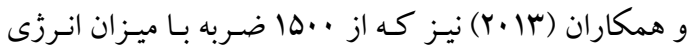

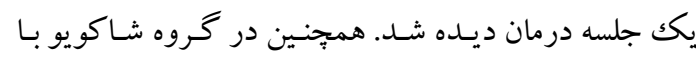
91/ • ميلى زول بر ميلىمتر مربـع در ناحيـه اتصـال تانـدون بـه شدت بالا، ماندكارى اثرات درمانى يكك هفته يس از درمـان عضله در سر داخلى و خـارجى عضـله كاسـترو كنميوس بــ نيز معنى داربود.

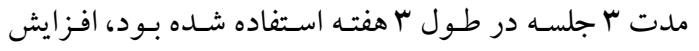
دامنه حركتى غيرفعال مج يا يس از استفاده از شاكويو ديدهشد(Y I). در اين مطالعـات علـت احتمـالى تـاثير شـاكويو در 
تعلداد جلسات درمانى و تكميل طول درمـان است زيـرا كـه فعال شـدن مكانيسـم عروقزايس وابسته بـه شـدت مناسـب اعمال ضـربات است. همجِنين در ايـن مطالعه عنوان شـده

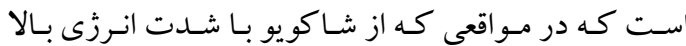
استفاده مىشود امكان آسيب بافتى از جمله تشكيل بافت-

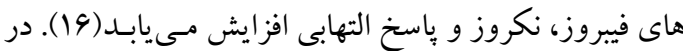
واقع ممكن است تاثير غيرمعنىدار شاكويو با شدت بايين در

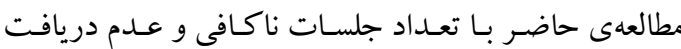
انرزى مناسب توسط بافت توجيه گردد. مطالعات بيشترى در زمينهى تعيـين آسـتانهى شـدت مـوثر در درمـان اسياستيسيته

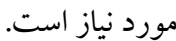
علىرغم تفاوت در شدت مورد استفاده از جريان شـاكويو و

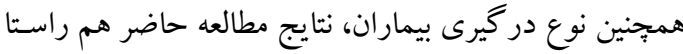

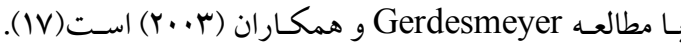
در مطالعـ Gerdesmeyer و همكــاران (r..r) تـاثيرات

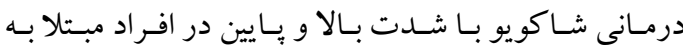

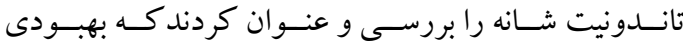
تانـدونيت و كـاهش شـدت درد بـهدنبـال اسـتفاده از شـدت

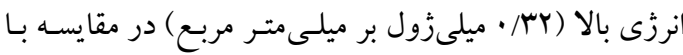

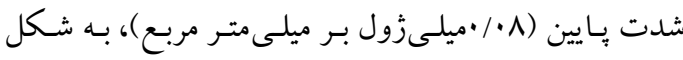

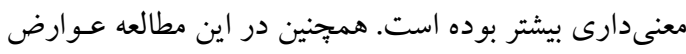

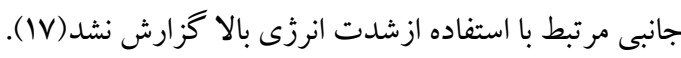

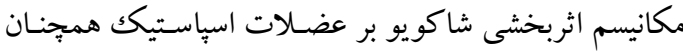

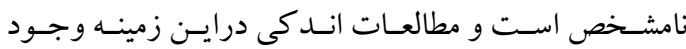
دارد(م). در برخى از اين مطالعات، به توليد نيتريك اكسايد

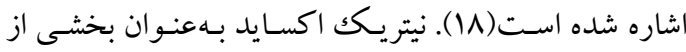

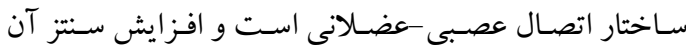
باعث بهبود انتقال سينايسى در سيستم عصبى مر كزى شـده و در بهبود حافظه نقش دارد. سـنتز نيتر يكك اكسـايد بـهنونوان

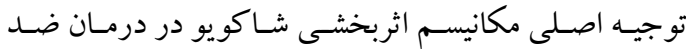

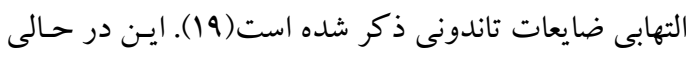
است كه در برخى مطالعات عنوان شده است كه بهبود انتقال
افزايش دامنه حر كتى، تاثير بـر بافتهـاى فيبروتيكك عنوان شده است، بدين شكل كه قرار گيرى طولانى مدت بافت در معرض اسياستيسيتى باعث ايجاد تغييراتى در بافت نرم مانند ايجاد بافتهاى فيبروتيكك و كلسيفه شدن آن مىشود. بنابر مطالعات آزمايشگاهى كه توسط Sohn و همكاران (Y.11) Manganotti با تاثيرى كـه بـر تحريكك توليـد بـيش فاكتورهـاى سـاخت

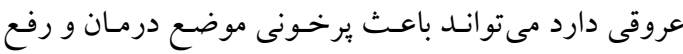

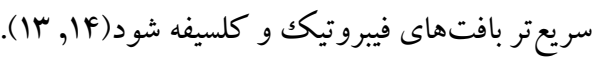

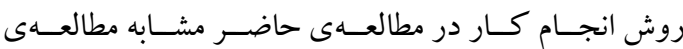
Manganotti جريان شاكويو بهمدت يك جلسه با ميز ان انرزى بـ/•ميلى-

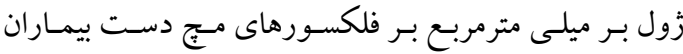
مبتلابه سكته مغزى استفاده گرديد(9). در مطالعه حاضـر در كروه درمانى با شـدت بـايين علىرغـم بهبودى در دامنهى

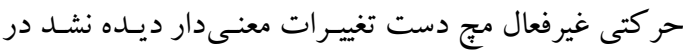

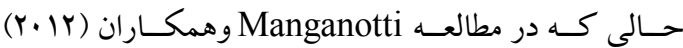

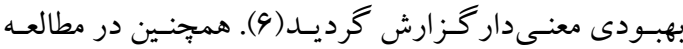

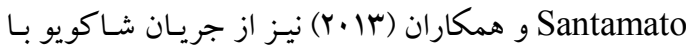

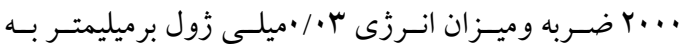
صـورت ها جلسـه در ها روز متـو الى در بيمـاران مبـتلا بـهـ

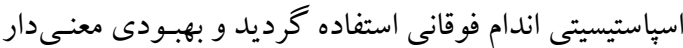
در دامنه حر كتى متج دست بيان شد (10).

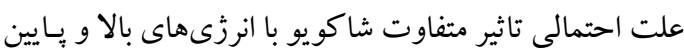

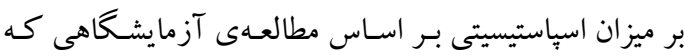

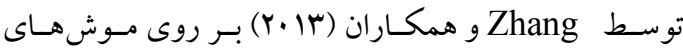

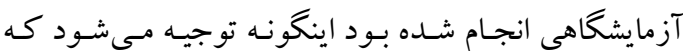
استفاده از شـاكويو در مـوشهـاى آزمايشـاهى بـا جريـان انرزى مناسب، موجب مهار رونويسى زن و توليد فاكتورهاى

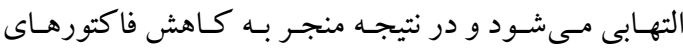
التهابى، افزايش انتشار عروقى و كاهش التهاب و فيبروز بافت مى شود. ايـن نتـايج وابسته بـه دوز درمـانى مناسـب و و

هبله علمى دانشكاه علوم بِزشكى كردستان / دوره بيست و شش / فروادين و ا(ديبرشت •ع|ا 

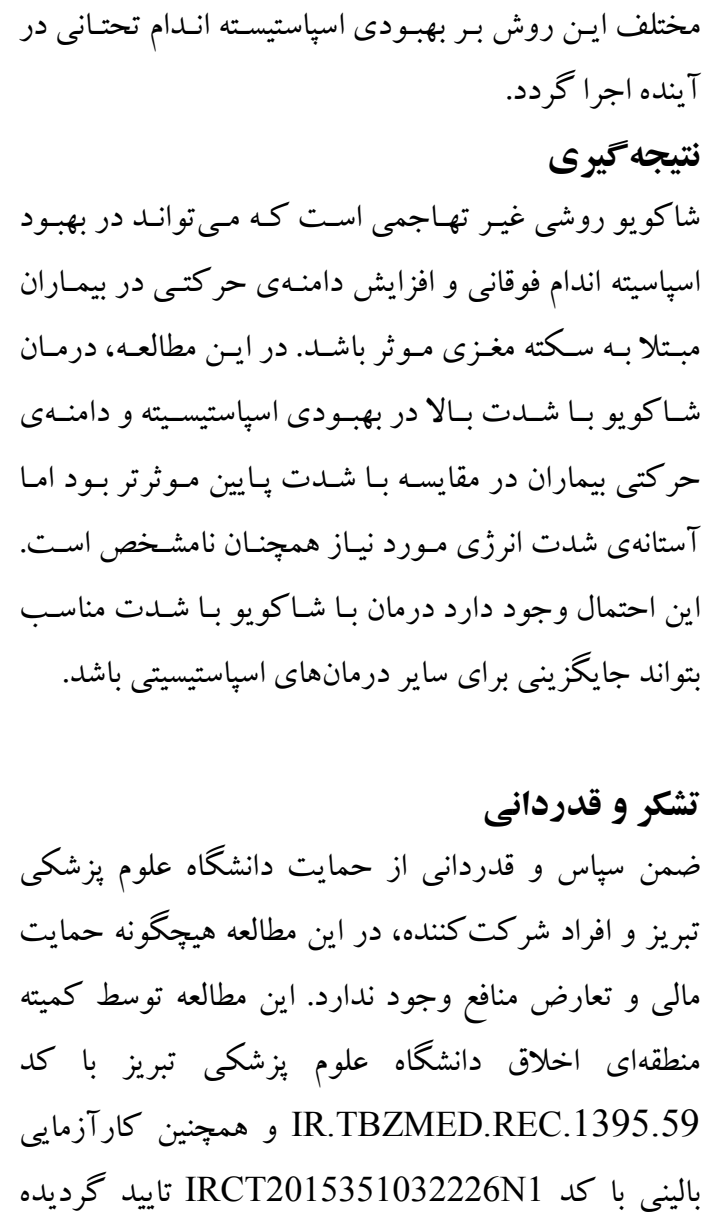

سينايسى ناشى از افزايش ترشح نيتر يـك اكسـايد در سيستم عصبى محيطى نمسى توانـلـ بـر اسياستيسيتى ناشى از سيستم عصسبى مركـزى تـاثيرى داشـته باشـــ(9). در مـورد تـاثير ويبراتورى شاكويو نيز عنوان شده است كه ويبريشن و فشـار

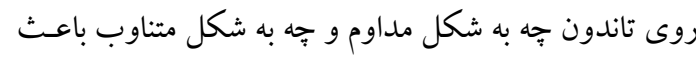

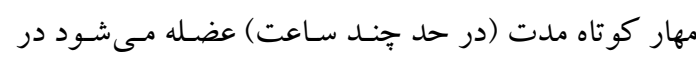
حالى كه بيشتر مطالعاتى كه در زمينه شاكويو انجام شـدهانــ

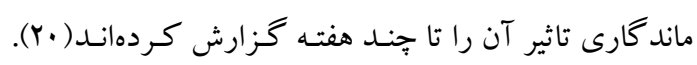

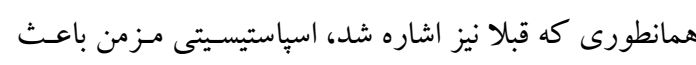
ايجاد بافتهـاى فيبروتيـك در عضـلات در گيـر مسى شـود و ممكـن اسـت اثربخشى شـاكويو ناشسى از تـاثير روى همسين

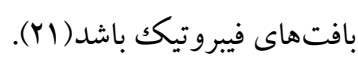
مطالعهى حاضر نيز همانتـد سـاير مطالعـات محسدوديتهـايى سيى

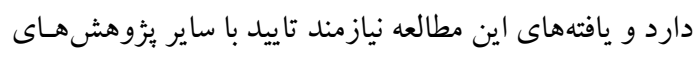
كلينيكى است. از جمله محدوديتهاى اين مطالعه مسىتوان

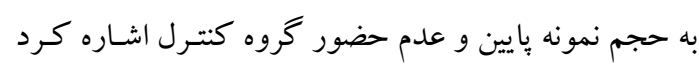
كه قدرت تعميميـذيرى نتـايج را كاهش مسىدهـد. بيشـنهاد مىشـود مطالعـات ديكـرى در ايـن زمينه بـا افز ايش تعـداد

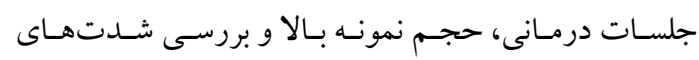

1.O'dwyer N, Ada L, Neilson P. Spasticity and muscle contracture following stroke. Brain. 1996;119(5):1737-49.

2.Lee J-Y, Kim S-N, Lee I-S, Jung H, Lee K-S, Koh S-E. Effects of extracorporeal shock wave therapy on spasticity in patients after brain injury: a meta-analysis. J Phys Ther Sci. 2014;26(10):16417.

3.Conditions NCCfC, editor Stroke: national clinical guideline for diagnosis and initial management of acute stroke and transient ischaemic attack (TIA). 2008; Royal College of Physicians.

4.Aho K, Harmsen P, Hatano S, Marquardsen J, Smirnov VE, Strasser T. Cerebrovascular disease in the community: results of a WHO collaborative study. Bull World Health Organ.1980;58(1):113.

5.Lance JW. The control of muscletone, reflexes, and movement: Robert Wartenbeg Lecture. Neurology. 1980;30(12):1303.

6.Manganotti P, Amelio E. Long-term effect of shock wave therapy on upper limb hypertonia in patients affected by stroke. Stroke. 2005;36(9):1967-71.

7.Santamato A, Francesca Micello M, Panza F, Fortunato F, Logroscino G, Picelli A, et al. Extracorporeal shock wave therapy for the treatment of poststroke plantar-flexor muscles spasticity: a prospective open-label study. Top Stroke Rehabil. 2014;21(sup1):1-24. 
8.Amelio E, Manganotti P. Effect of shock wave stimulation on hypertonic plantar flexor muscles in patients with cerebral palsy: a placebo-controlled study. J Rehabil Med. 2010;42(4):339-43.

9.Trompetto C, Avanzino L, Bove M ,Marinelli L, Molfetta L, Trentini R, et al. External shock waves therapy in dystonia: preliminary results. Eur J Neurol. 2009;16(4):517-21.

10.Troncati F, Paci M, Myftari T, Lombardi B. Extracorporeal shock wave therapy reduces upper limb spasticity and improves motricity in patients with chronic hemiplegia: a case series. NeuroRehabilitation. 2013;33(3):399-405.

11.Abolhasani H, Ansari NN, Naghdi S, Mansouri K, Ghotbi N, Hasson S. Comparing the validity of the Modified Modified Ashworth Scale (MMAS) and the Modified Tardieu Scale (MTS) in the assessment of wrist flexor spasticity in patients with stroke: protocol for a neurophysiological study. BMJ open. 2012;2(6):e001394.

12.Moon SW, Kim JH, Jung MJ, Son S, Lee JH, Shin H, et al. The effect of extracorporeal shock wave therapy on lower limb spasticity in subacute stroke patients. Ann Rehabil Med. 2013;37(4):461. 13.Sohn MK, Cho KH, Kim Y-J, Hwang SL. Spasticity and electrophysiologic changes after extracorporeal shock wave therapy on gastrocnemius. Ann Rehabil Med. 2011;35(5):599.

14.Manganotti P, Amelio E, Guerra C. Shock wave over hand muscles: a neurophysiological study on peripheral conduction nerves in normal subjects. Muscles Ligaments Tendons J. 2012;2(2):104.

15.Santamato A, Notarnicola A, Panza F, Ranieri M, Micello MF, Manganotti P, et al. SBOTE study: extracorporeal shock wave therapy versus electrical stimulation after botulinum toxin type a injection for post-stroke spasticity-a prospective randomized trial. Ultrasound Med Biol. 2013;39(2):283-91.

16.Zhang X, Yan X, Wang C, Tang T, Chai Y. The dose-effect relationship in extracorporeal shock wave therapy: The optimal parameter for extracorporeal shock wavetherapy. J Surg Res. 2014;186(1):484-92.

17.Gerdesmeyer L, Wagenpfeil S, Haake M, Maier M, Loew M, Wörtler K, et al. Extracorporeal shock wave therapy for the treatment of chronic calcifying tendonitis of the rotator cuff: a randomizedcontrolled trial. JAMA. 2003;290(19):2573-80.

18.Gotte G, Amelio E, Russo S, Marlinghaus E, Musci G, Suzuki H. Short-time non-enzymatic nitric oxide synthesis from L-arginine and hydrogen peroxide induced by shock waves treatment. FEBS letters. 2002;520(5):1-3.

19.Molina JA, Jiménez-Jiménez FJ, Ortí-Pareja M, Navarro JA. The role of nitric oxide in neurodegeneration. Drugs \& aging. 1998;12(4):251-9.

20.Leone JA, Kukulka CG. Effects of tendon pressure on alpha motoneuron excitability in patients with stroke. Physical therapy. 1988;68(4):475-80.

21.Rompe JD, Decking J, Schoellner C, Nafe B. Shock wave application for chronic plantar fasciitis in running athletes: a prospective, randomized, placebo-controlled trial. Am J Sports Med. 2003;31(2):268-75. 